Fanum

Sociológico
Forum Sociológico

Série II

$18 \mid 2008$

Explorando os interstícios urbanos

\title{
Gentrificação e a Cidade Revanchista: que lugar para os Movimentos Sociais Urbanos de Resistencia?
}

\section{Luís Mendes}

\section{(2) OpenEdition \\ Journals}

Edição electrónica

URL: https://journals.openedition.org/sociologico/226

DOI: $10.4000 /$ sociologico.226

ISSN: 2182-7427

Editora

CICS.NOVA - Centro Interdisciplinar de Ciências Sociais da Universidade Nova de Lisboa

\section{Edição impressa}

Data de publição: 1 junho 2008

Paginação: 21-28

ISSN: 0872-8380

Refêrencia eletrónica

Luís Mendes, «Gentrificação e a Cidade Revanchista: que lugar para os Movimentos Sociais Urbanos de Resistencia?», Forum Sociológico [Online], 18 | 2008, posto online no dia 03 dezembro 2012 consultado o 30 março 2022. URL: http://journals.openedition.org/sociologico/226 ; DOI: https:// doi.org/10.4000/sociologico.226

Este documento foi criado de forma automática no dia 30 março 2022

(c) CICS.NOVA 


\title{
Gentrificação e a Cidade Revanchista: que lugar para os Movimentos Sociais Urbanos de Resistencia?
}

\author{
Luís Mendes
}

\section{Introdução}

1 Os primeiros sintomas da crise do welfare state começaram a manifestar-se por volta de meados dos anos 70. A partir de então, a gradual desagregação do modelo predominante de intervenção pública fez-se paralelamente à superação do fordismo pelo pós-fordismo, tornando cada vez mais difícil para o Estado reunir os recursos necessários para garantir a intervenção da despesa pública ao mesmo ritmo que se atingira em anos anteriores. À precariedade da situação laboral dos trabalhadores mais desqualificados e dos grupos sociais mais desfavorecidos, acumulou-se a desregulação do mercado de habitação e do uso do solo urbano, que tende a valorizar um padrão mais aleatório na produção temporal e espacial dos acontecimento urbanos e o fabrico de uma segregação residencial a escalas mais finas. Este padrão é produto social do jogo do mercado imobiliário pouco regulado, de processos especulativos de valorização. 0 governo urbano orienta-se por um modelo gestionário (gestão estratégica importada do meio empresarial) em que o uso dos recursos públicos se faz para atrair investimento, o fornecimento dos serviços passa a fazer-se pelo mercado e pelo sector privado e são valorizadas as parcerias público-privadas.

2 A propósito do desmantelamento das políticas de assistência pública como tentativa de incutir alento à iniciativa económica dos privados, de que o neoliberalismo dos governos urbanos das cidades de países de capitalismo desenvolvido e maduro se tem vindo a revestir; e de como a crise do welfare state está associada também à afirmação de intenções conservadoras, responsáveis pela produção de transformações no governo da 
cidade, discutiremos o conceito de cidade revanchista, de acordo com Neil Smith (1996). Este conceito denuncia como o discurso "regenerativo" da gentrificação no âmbito de políticas urbanas de valorização da imagem da cidade, ainda que vise a fixação da população já existente, a modernização do tecido económico, o aumento do emprego e o crescimento económico; não deixa também de funcionar como mecanismo de legitimação do poder instituído e da mobilização de grande investimento público que, em última análise, é desviado do auxílio aos mais carenciados, funcionando como subsídio aos mais ricos (Banca, instituições financeiras, grandes grupos económicos e de construção civil, empreendedores, governantes, etc.).

3 Neste contexto, o objectivo deste artigo é o de discutir o papel que cabe aos movimentos sociais urbanos na resistência aos novos produtos imobiliários fabricados pelas várias tendências de regeneração urbana na cidade contemporânea, especialmente na gentrificação da cidade centro. Tratando-se de um ensaio teórico e exploratório desta problemática, desprovido de fundamentação empírica directa, o texto segue uma metodologia hipotético-dedutiva, pelo que a sua construção parte de postulados ou conceitos já estabelecidos na literatura consultada, através de um trabalho lógico de relação de hipóteses, que configura, a nosso ver, uma possível perspectiva de interpretação dos fenómenos em estudo. Argumentaremos que a ocupação ilegal de propriedades vagas ou desocupadas à margem da ordem estabelecida (ou melhor, contra ela) e a oposição ao desalojamento têm o seu ponto de partida numa crise estrutural do alojamento. Todavia, não se podem considerar estas aç̧ões como uma simples resposta mecânica a uma ausência de habitação, sendo que se trata de um processo social estreitamente ligado à relação dialéctica entre as relações de classe e as estratégias políticas para a habitação no centro da cidade. Concluiremos com a ideia de que os actores desta luta urbana apenas exercem um domínio parcial das mudanças que suscitam ou que se esforçam por inflectir, caso não se insiram numa acção concertada e integrada politicamente.

\section{Crise do Estado-Providência, ofensiva neoliberal e a produção da cidade revanchista}

Neste ponto apresentam-se as principais transformações ocorridas nos princípios de organização do sistema económico e de regulação que marcaram a transição do regime de acumulação fordista apoiado no keynesianismo, dominante nos países e metrópoles ocidentais entre o pós-Segunda Guerra Mundial e os anos 70, para o regime de acumulação flexível, que se inscreve num quadro económico largamente marcado pelo neoliberalismo e que, em grande parte, como veremos, explica a emergência, proliferação e reforço das tendências da gentrificação nas últimas décadas do século $\mathrm{XX}$.

5 Nos anos 60 e 70, a expansão e consolidação do Estado-Providência deram-se no sentido da diversificação da oferta estatal de bens e serviços sociais e da elevação do valor dos benefícios e da qualidade da oferta. A persistência da desigualdade e a emergência de novas procuras parecem ter sido em larga medida contra-atacadas pela consolidação e expansão dos direitos sociais, tendo sido esta a época da discriminação positiva, dos programas de combate à pobreza, da melhoria dos serviços sociais e do fomento do valor dos benefícios e transferências. O pacto fordista e o welfare state. O fordismo representou indiscutivelmente algo mais do que um modelo de desenvolvimento 
económico. Na verdade, a natureza desse modelo favoreceu a emergência de um conjunto bem definido de actores sociais e reuniu as condições para a criação de esquemas típicos de regulação das relações entre eles. A partir dos anos 40 do século $\mathrm{XX}$, o Estado tornou-se um protagonista importante na intervenção assistencial junto dos segmentos da população mais desfavorecida. Esta intervenção generalizou-se e difundiu-se, embora em diversas modalidades e intensidades geograficamente díspares, em quase todos os países desenvolvidos. Tornou-se popular a expressão welfare state para designar a orientação da política estatal em que o poder organizado se emprega deliberadamente para modificar o movimento das forças de mercado em pelo menos três direcções: garantindo aos indivíduos e às famílias um rendimento mínimo; reduzindo o grau de insegurança e colocando os indivíduos e as famílias em condições de enfrentar determinadas contingências sociais (por exemplo, a doença, a velhice, o desemprego), que, de contrário, conduziriam a crises individuais e familiares; assegurando que sejam oferecidos a todos os cidadãos os melhores padrões possíveis de uma gama moderada dos serviços sociais (Mela, 1999).

6 As políticas keynesianas acompanharam e estimularam a urbanização fordista - no ver de Ascher (1998), ou a urbanização do período da Modernidade Universal, na leitura de Harvey (1989) - desenvolvendo uma cidade do "bem-estar" (do welfare state), de forma a assegurar o pacto fordista entre patronato e assalariados, de maneira a que a ordem social se mantivesse e o sistema capitalista se reproduzisse. Tal era conseguido através do estímulo estatal à economia por via do financiamento público dos equipamentos colectivos e da habitação social e favorecendo a industrialização das actividades de construção e de obras públicas através de encomendas maciças e repetitivas. No entanto, esta forma de produzir o espaço urbano e toda a coerência fordista estão, actualmente, em crise (Ascher, 1998).

7 Os primeiros sintomas da crise do welfare state começaram a manifestar-se por volta de meados dos anos 70 , se bem que não se produza em todos os países, nem simultaneamente, nem com ritmo similar. A partir de então, a gradual desagregação do modelo predominante de intervenção pública fez-se paralelamente à superação do fordismo pelo pós-fordismo, tornando cada vez mais difícil para o Estado reunir os recursos necessários para garantir a intervenção da despesa pública ao mesmo ritmo que se atingira em anos anteriores. À inevitável precariedade da situação laboral dos trabalhadores mais desqualificados e dos grupos sociais mais desfavorecidos, acumulou-se a desregulação do mercado de habitação e do uso do solo urbano, que tende a valorizar um padrão mais aleatório na produção temporal e espacial dos acontecimentos urbanos. Este padrão é simplesmente produto social do jogo do mercado imobiliário pouco regulado, de processos especulativos de valorização, e não tanto das condições locais em termos de distância ao centro ou a zonas de emprego, do nível local do comércio, de equipamentos ou da qualidade do ambiente. 0 governo urbano orienta-se por um modelo gestionário (gestão estratégica importada do meio empresarial) em que o uso dos recursos públicos se faz para atrair investimento, o fornecimento dos serviços passa a fazer-se pelo mercado e pelo sector privado e são valorizadas as parcerias público-privadas (Hall, 1998).

8 Ao Estado produtivista e bastante interventivo, embora com variantes consoante os países, sucedeu um Estado que procurou transferir muitos serviços para a esfera privada (transportes, habitação, redes de distribuição de comunicações e de electricidade...), acentuando a ideia, quantas vezes aparente, de efectuar uma regulação 
mais eficaz das actividades económicas (através de legislação, de fiscalização, da instalação de comissões reguladoras do mercado bolsista, das telecomunicações, etc.). Este mesmo Estado, que nos anos 80 e 90 foi marcado pelo quadro de referências neoliberal que ainda hoje tem um peso significativo (Smith, 1989; Pimenta de Faria, 2002), reforçou as lógicas competitivas de carácter territorial (Domingues, 1996; Peck e Tickell, 2002) e das políticas de habitação (Wexler, 1996, 1999). À crise das grandes cidades que marcou o final do ciclo económico do pós-guerra, sucedeu uma nova política urbana, muito mais orientada para o mercado e, portanto, marcada pelas lógicas da promoção do consumo, da competitividade entre metrópoles, do protagonismo dos actores privados no processo de planeamento e de produção da cidade (Ley, 1980; Barata Salgueiro, 1999; Hall e Hubbard, 1996).

É um facto que associado aos primeiros sintomas da crise do welfare state e emergência do neoliberalismo, por volta dos anos 80 , mas sobretudo 90 e recentes em Portugal, designadamente à desagregação daquele modelo de intervenção pública, esteve a origem de novas e crescentes desigualdades sociais, que tendem a agravar-se com a tendência vigente dos países de desenvolvimento mais avançado para regredirem da fiscalidade directa para a indirecta, ou, pelo menos, para reforçarem a pressão fiscal sobre os rendimentos do trabalho em benefício dos rendimentos do capital. A propósito do desmantelamento das políticas de assistência pública como tentativa de incutir alento à iniciativa económica dos privados, de que o neoliberalismo dos governos urbanos se tem vindo a revestir; e de como a crise do welfare state está associada também à afirmação de intenções conservadoras, responsáveis pela produção de transformações radicais no governo da cidade, Smith defende o conceito de cidade revanchista, referindo:

"Las enormes subvenciones concedidas al capital mundial; la destrucción y el desmantelamiento sistemático de servicios públicos (por ejemplo, la educación) y la crisis de la reproducción social; y las nuevas ambiciones políticas de las ciudades en la economía global. [...] El argumento general que deseo plantear aquí es que la ciudad revanchista [...] forma parte de todo un nuevo régimen de desarrollo desigual que encaja com el nuevo globalismo. Conjuntamente con una mayor represión política, representa elementos centrales de un nuevo régimen de desarrollo desigual que se vuelve cada vez más visible en las economías capitalistas avanzadas". (2005: 75)

Imbuído de um papel de intervenção e crítica social, Smith (1996) denuncia que o discurso "regenerativo" da gentrificação no âmbito de políticas de valorização da imagem do espaço urbano ainda que vise a fixação da população já existente, a modernização do tecido económico, o aumento do emprego e o crescimento económico; a verdade é que não deixa também de funcionar como mecanismo de legitimação do poder instituído e da mobilização de grande investimento público que, em última análise, é desviado do auxílio aos mais carenciados, funcionando como subsídio aos mais ricos (Banca, instituições financeiras, grandes grupos económicos e de construção civil, empreendedores, governantes, etc.). Parte-se da dedução preliminar de que na sociedade capitalista o conjunto de leis que a regem é necessariamente burguês (sob domínio das classes dominantes) e existe para servir os interesses do capital e não da maioria social. $\mathrm{O}$ mesmo pode ser dito do Estado, que, mesmo sob o disfarce liberal e formalmente voltado (no sentido de discurso teórico) para o interesse de toda a sociedade, representa particularmente sob este modo de produção a dominação da 
"classe burguesa", isto é, dos grupos de maior estatuto social e económico e dos interesses do capital (Lefebvre, 1968).

As intervenções públicas que provocam valorização do espaço urbano desencadeiam mecanismos contraditórios de expulsão e de reapropriação. As novas políticas urbanas traduzem uma maior orientação para o mercado e para os consumidores, em detrimento das classes mais desfavorecidas. A selectividade dos investimentos favorável à reprodução do capital implica o abandono, o esquecimento e a menor atenção à "cidade da maioria", com particular gravidade para as áreas mais carenciadas onde se concentram os mais desfavorecidos (Brenner e Theodore, 2002; Jessop, 2002). É a emergência da cidade "revanchista" produzida pela ofensiva neoliberal e tese que Smith tem explorado mais recentemente $(1996,2001,2002)$. O autor desvendou, desta forma, a máscara social de compreensão e "bondade institucional" inerentes a estes recentes produtos imobiliários da nova gestão urbana, argumentando como estes promovem uma lógica de controlo social favorável à reprodução do capital e às classes dominantes.

\section{Os movimentos sociais urbanos de resistência às novas formas de gentrificação}

12 Segundo Savage e Ward (1993), para que haja gentrificação no espaço urbano, tem de se dar uma coincidência de quatro processos: i) uma reorganização da geografia social da cidade, com substituição, nas áreas centrais da cidade, de um grupo social por outro de estatuto mais elevado; ii) um reagrupamento espacial de indivíduos com estilos de vida e características culturais similares; iii) uma transformação do ambiente construído e da paisagem urbana, com a criação de novos serviços e uma requalificação residencial que prevê importantes melhorias arquitectónicas; iv) por último, uma mudança da ordem fundiária, que, na maioria dos casos, determina a elevação dos valores fundiários e um aumento da quota das habitações em propriedade. Já Neil Smith insiste no facto de o processo de gentrificação resultar, em parte, do desenvolvimento irregular e flexível do mercado do solo urbano, integrando-se no processo de acumulação de capital. O abandono e a degradação da cidade centro, de acordo com o autor, cria justamente a futura oportunidade de valorização e negócio imobiliário nos bairros centrais, tornando-os atractivos para o investimento público e privado e para a exploração de mais-valias resultantes da diferença entre a actual renda capitalizada face ao presente uso do seu solo e a renda que potencialmente poderá a vir a ser capitalizada tendo em conta a sua localização central (Smith, 1979, 1987)1.

Desde há cerca de 30 anos, o conceito de gentrificação vem assim designar este novo processo de recomposição (e substituição) social verificado no espaço urbano, ligado muitas vezes a acções de reabilitação urbana das habitações nos centros antigos das cidades, mediante investimentos estatais ou privados. Na verdade, indica um processo de emburguesamento de bairros históricos, ou seja, uma acentuação da conotação residencial alto-burguesa ou mesmo uma transformação nesse sentido de bairros anteriormente conotados de maneiras diferentes. Trata-se de um fenómeno de substituição social classista e de reapropriação pela burguesia dos espaços de habitat populares das áreas antigas centrais, que implica expulsão dos antigos residentes, logo segregação residencial, culminando com um aprofundamento da divisão social do espaço urbano. Estas tendências são muito evidentes numa extensão do conceito de 
gentrificação a casos de renovação e regeneração, levadas a cabo por diversos agentes de produção do espaço urbano, já caracterizados por Lefebvre (1974): os proprietários fundiários, os promotores imobiliários, o Estado, as empresas e os cidadãos.

A gentrificação não é um fenómeno novo, contudo as suas actuais formas distinguem-se dos primeiros episódios pontuais que se restringiam à cidade centro. As principais diferenças entre as novas formas de gentrificação dos anos 90 e a forma clássica do fenómeno do início dos anos 70 são a escala e a extensão. Diversos estudos urbanos nos últimos quinze anos têm relacionado o processo de gentrificação com as numerosas intervenções de renovação e regeneração urbanas verificadas ao longo dos anos 80 e 90 em muitas cidades e por vezes favorecidas ou mesmo incentivadas pelas intenções políticas neoliberais dos governos urbanos (Hackworth, 2007).

A gentrificação, nestes casos, sofre mutações, pois deixa de estar única e exclusivamente associada à reabilitação urbana e passa a estar cada vez mais ligada à regeneração ou mesmo à renovação de inteiros bairros de habitação, situados no centro ou nas suas proximidades e na sua substituição por conjuntos de construções de luxo, integrados, com serviços qualificados, ou outras modalidades de residências de alta qualidade, novos produtos imobiliários destinados a camadas de rendimentos elevados (Davidson e Lees, 2005; Lees, Slater e Wyly, 2008).

16 Smith $(1996,2001,2002)$ deixa claro que os projectos de regeneração urbana, que suportam a promoção ideológica da gentrificação, alimentam equívocos vários no que diz respeito às supostas intenções iniciais de reabilitação habitacional e integração/ fixação da população de menor estatuto socio-económico já anteriormente residente nos bairros históricos alvo de intervenção. De resto, nesses contextos, o filtering up que a gentrificação pressupõe - pelo processo de substituição social que implica, de classes de menor estatuto socio-económico pelas de maior - faz antever o acentuar dos traços de segregação sócio-espacial nas áreas onde o fenómeno tem lugar. Nestes termos, ao mesmo tempo que produto social e meio, o espaço é também instrumento da acção, meio de controle, logo, de dominação e de poder, que produz simultaneamente uma hierarquia dos lugares centrada no processo de acumulação, uma (re)centralização do poder. 0 desenvolvimento de parcerias público-

-privadas que neste quadro é frequente desenhar-se constitui um verdadeiro subsídio aos mais ricos, ao tecido empresarial mais poderoso e às funções e relações estratégicas de controlo, poder e dominação do espaço urbano, condição fundamental na perpetuação da reprodução do capital, premissa essencial para o suporte do sistema de produção e consumo capitalista. Tudo isto à custa dos investimentos em serviços locais de consumo colectivo. É que se, em última análise, a atraç̧ão e o crescimento propiciados pela gentrificação a todos beneficiam, em primeiro lugar ganham os promotores imobiliários e as empresas, muito frequentemente à custa da expulsão dos residentes e das empresas mais débeis dos lugares requalificados, lançados por via desta (des)valorização num processo de exclusão e de marginalidade sócio-espacial. Algo directamente correlacionado com modelações ideológicas que visam a manutenção da reprodução social das classes de maior estatuto socio-económico.

Neste processo, Castells (1978) ressalta a crise estrutural que atravessa o sistema capitalista após a crise petrolífera, o que limita os investimentos públicos por falta de recursos financeiros à disposição do Estado. Perante o emagrecimento das receitas, o Estado vê-se forçado a adoptar políticas de contracção de investimento, correspondendo-lhe na razão inversa a aceleração da crise urbana. Sem recursos 
financeiros necessários para responder às necessidades em matéria de alojamento, transportes e equipamentos sociais da população, o Estado tenderá a concentrar o investimento nas funções urbanas necessárias ao regime capitalista. Face às contradições urbanas geradas pela omnipresença da crise económica e financeira, outra coisa não seria de esperar do que o recrudescimento dos movimentos reivindicativos urbanos, fazendo depender a capacidade transformadora destes movimentos da articulação com a luta de classes e com o processo de política urbana local daí resultante, como aconteceu com os movimentos populares de luta por casa e pelo direito à cidade no pós-25 de Abril em Portugal.

Historicamente praticadas por populações sem voz e sem capacidade de se fazerem ouvir, as ocupações em geral e as de casas vagas em particular, que aconteceram e ainda acontecem em Portugal - sejam elas motivadas ou não por movimentos sociais urbanos anti-gentrificação - ficam muito aquém do movimento de squatters que muitos países conheceram desde o pós-guerra (Castells, 1973; Schecter, 1978; Pruijt, 2003). As ocupações constituem nesses países uma resposta às políticas desenfreadas de reestruturação e reabilitação dos bairros centrais onde a terciarização e a nova classe média exercem uma fortíssima pressão no sentido do desalojamento da população já instalada e, portanto, do agravamento da segregação residencial. Ainda que limitada em termos de elementos e de localidades envolvidas, esta movimentação dos moradores introduziu ruptura e descontinuidade no sistema social, forçando a adopção de medidas políticas que respondessem às necessidades das populações carenciadas. Estes movimentos sociais resultam de relações de classe e exprimem o conflito que orienta uma classe contra outra para apropriar-se e conservar o espaço urbano, enquanto espaço quotidiano da reprodução da força de trabalho e de vida social.

Partindo, assim, do princípio da divisão do campo social em dois blocos fundamentais (as classes dominantes e as classes dominadas, representativas do capital e do trabalho, respectivamente), Manuel Castells $(1973,1977,1978)$ faz emergir o aparelho políticoideológico como suporte das classes dominantes e a luta política como recurso das classes dominadas, construindo a sua teoria dos movimentos sociais urbanos a partir da relação dialéctica e contraditória de interesses entre Estado (como agente da classe capitalista) e sociedade civil, bem como tendo as desigualdades e os bloqueios ao consumo colectivo como fonte primordial de contradições e crises urbanas geradoras de lutas e conflitos.

Manuel Castells define lutas urbanas como práticas reivindicativas que tentam modificar ou alterar as contradições que atravessam a cidade capitalista. Quando existe a convergência destas lutas com as lutas operárias, assiste-se ao aparecimento de movimentos sociais urbanos. Estes, também segundo o autor, são práticas específicas das lutas urbanas com capacidade para transformar a lógica urbana estruturalmente dominante (Pickvance, 2003). Para muitos autores que se têm vindo a debruçar sobre esta problemática (ex: Castells, Touraine, etc.), um dos pressupostos estruturantes a reter a propósito dos movimentos sociais urbanos é o de que estes participam da capacidade transformadora do movimento de massas em virtude da correlação de forças que se estabelecem no seu seio. Sem essa articulação de acções com o movimento operário - centro de gravidade das lutas históricas - as lutas urbanas perderão todo o seu potencial transformador. Existe assim a necessidade de alargamento das lutas urbanas a toda uma multiplicidade de contradições urbanas que lhe confiram legitimidade de organização. Tal organização só poderá processar-se na base do 
respeito e apoio mútuos perante o valor próprio de cada campo de luta para os diferentes grupos de pressão implicados (Köhler e Wissen, 2003; Miller, 2007).

Sabe-se que as reformas pretendidas pelos movimentos sociais urbanos só poderão abrir o caminho a uma verdadeira transformação social em função da relação de forças que ela consiga impor. Esta relação de forças é função da capacidade de alargamento da aliança de classes e da existência de uma linha política justa, susceptível de unir as diferentes lutas. Assim, a integração dos movimentos sociais urbanos nas forças políticas é aconselhável, caso contrário os grupos de pressão por habitação condigna, embora dispondo de possibilidades traduzidas na posse de algumas competências reivindicativas, não dispõem de capacidade para negociar e contestar, encontrando-se desprovidos de capacidades para saberem situar-se no jogo social e explorarem o quadro legal-institucional (Nicholls, 2008; Köhler e Wissen, 2003). Estabelecer este tipo de articulação não é fácil. Embora as lutas urbanas e os grupos de pressão abram possibilidade de novas alianças, a organização actual da vida urbana subjugada ao controlo social imposto pelas políticas municipais de requalificação sócio-urbanística do Estado capitalista barra-lhes o caminho e desmobiliza o seu movimento de oposição e resistência (Mayer, 2007).

\section{Considerações finais}

A forma e a intensidade da articulação do processo social das lutas urbanas por habitação na cidade centro com o processo que tem por base outras contradições da estrutura social revelam a capacidade de transformar, por meio destas práticas, o conjunto das relações de classe, ou, se quisermos, a sua eficácia própria enquanto movimento social urbano. E isto, não do ponto de vista da influência que as lutas urbanas podem ter sobre a mobilização política individual dos habitantes da cidade, mas antes em relação à convergência do movimento de práticas reivindicativas urbanas com as lutas sociais suscitadas por outros problemas sociais e políticos.

Os novos movimentos sociais que têm surgido nas sociedades ocidentais a partir dos anos 80 caracterizam-se por uma natureza heterogénea; carácter localizado, disperso e efémero; radicalismo e espectacularidade das acções; e ausência de ideologias programáticas. 0 esbatimento dos conflitos de base classista (sobretudo o operário), a fragmentação e a precarização da relação salarial e da situação perante o emprego, a massificação e simultânea individualização dos consumos e dos estilos de vida, a atomização e fragmentação dos comportamentos quotidianos, a ausência de partilha dos problemas/projectos colectivos e consequente desvanecimento da identidade colectiva e do sentido de partilha no seio da comunidade, todos estes factores contribuem para que se experimente uma crescente perda de capacidade mobilizadora das tradicionais estruturas associativas (sindicais, partidárias, etc.) (Estanque, 1999).

Apesar da sua fraca capacidade de mobilização, do seu carácter limitado e fugaz, a verdade é que não raras vezes os novos movimentos sociais urbanos comportam inovação social e política, encetada por vanguardas poderosas. 0 surgimento de novas contradições sociais consideradas pela economia política marxista como secundárias (minorias várias, mulheres, ambiente, etc.) conduziu à necessidade de libertar o conceito de movimento social urbano da sua carga ideológica e da dependência tutelar do movimento operário, o que não representa necessariamente uma fraqueza, pois ainda que se assista a uma multiplicação de pequenos grupos incapazes de se organizar, 
frequentemente demasiado radicais, a verdade é que esta desorganização pode ser uma condição de êxito no início de formação do movimento (Stahre, 2004). Todavia, por natureza contínuo, um movimento social urbano não pode existir sem forças sociais e instituições de enquadramento organizacional. À medida que os movimentos sociais urbanos se vão expandindo e ganhando força política, à medida que se estruturam os seus programas de orientação ideológica e se consolidam as suas bases organizativas, a sua componente formal reforça-se, pelo que as conquistas alcançadas tendem a apresentar uma relação directa com o progressivo enquadramento institucional do movimento. Mesmo as comunidades contemporâneas que promovem a cidadania participativa e a democracia de proximidade não existem fora das determinantes estruturais das formações sociais. Nesta medida, para se oporem aos poderes hegemónicos capitalistas da ofensiva neoliberal em meio urbano precisam de uma representação de si mesmas e de meios institucionais para ampliar a sua base social de participação e mobilização.

25 Em rigor, trata-se de realçar a passagem do movimento de moradores de uma fase inicial de acções localizadas e espontâneas a uma outra fase caracterizada já por um projecto e um discurso de intervenção global na cidade. Este percurso não se verificou recentemente, quando se considera a fraca resistência ao já por si fraco, lento e gradual avanço da gentrificação nos bairros históricos da Capital, pois mesmo considerando a dinâmica de todas as frentes de acção urbana mais radicais de luta pelo direito à habitação (ocupações de casas devolutas e recusa de rendas especulativas), está-se na presença de lutas urbanas que não chegam a configurar um movimento social. De facto, a sua breve duração, o seu carácter espontâneo, a natureza secundária e embrionária dos seus efeitos imediatos, e a sua forma organizacional precária acabam por envolver um número não muito significativo de moradores. $\mathrm{O}$ peso do efémero e a falta de organização surgem como elementos inibidores da força transformadora que as ocupações podem transportar.

Segundo o amplo e profundo estudo de Carlos Vieira de Faria (2009), e reforçando a tese do estudo pioneiro de Vítor Matias Ferreira (1975), os dados provam que o movimento de ocupação de casas vacantes não passou de um conjunto de acções, individuais na maioria dos casos, cujo alcance para os próprios terminava no momento seguinte após o êxito da ocupação, pelo que se deve interpretar o fenómeno mais como um movimento de protesto político-institucional. Na verdade, este último autor assegura que o carácter parcelar das lutas urbanas dificultou a criação de formas estruturadas com outras frentes de luta social, esvaziando-lhes o potencial subversivo da ordem urbana dominante. Na realidade, não houve do lado dos ocupantes empenhados neste processo, a iniciativa de constituição de nenhuma força social com capacidade para, a nível da cidade, concretizar uma organização que pudesse dar continuidade e sentido ao movimento. Contudo, é interessante registar que se trataram de lutas urbanas que durante o período revolucionário de 1974 marcaram, mesmo assim, uma agenda política, tendo obrigado os Governos Provisórios a legislar sobre financiamento prioritário ao sector da habitação e sobre o congelamento de rendas praticadas em meio urbano.

Assim, a verdadeira origem da mudança e da inovação da cidade está nos movimentos sociais urbanos e não necessariamente nas instituições (Drakakis-Smith, 1989). Resta saber se é possível uma mudança do urbano independentemente de uma mudança política e institucional global. Se é claro que não há transformação profunda possível da 
lógica e estrutura de uma sociedade sem haver transformação da dominação de classe e sem a consequente alteração na relação do poder político, pode haver no processo geral de transformação (que não tem de passar pela tomada de poder) fases e batalhas particulares que podem mudar, de maneira sempre instável e parcial, a lógica geral da organização urbana. É a relação entre linha política e lutas urbanas que está de facto no primeiro plano dos processos de mudança social potenciados pelos movimentos sociais urbanos. É no lugar do grupo social mobilizador do movimento nas relações de classe e nas características político-ideológicas da organização interveniente que se encontra o segredo último de um movimento social urbano e da reforma no domínio do Urbano.

\section{BIBLIOGRAFIA}

ASCHER, F. (1998), Metapolis. Acerca do Futuro da Cidade, Oeiras, Celta Editora.

BRENNER, N. e N. Theodore (2002), "Cities and the geographies of actually existing neoliberalism", in N. Brenner e N. Theodore (eds.), Spaces of Neoliberalism: Urban Restructuring in North America and Western Europe, Oxford, Blackwell, pp. 2-32.

CASTELLS, M. (1978), "Collective consumption and urban contradictions in advanced capitalism", in I. Susser (eds.) (2002), The Castells Reader on Cities and Social Theory, Oxford, Blackwell, pp. 107-129.

CASTELLS, M. (1977), The Urban Question, Londres, Edward Arnold.

CASTELLS, M. (1973), Luttes Urbaines et Pouvoir Politique, Paris, Maspero.

DAVIDSON, M. e L. Lees (2005), "New build gentrification and London's riverside renaissance", Environment and Planning A, 37 (6), pp. 1015-1032.

DOMINGUES, A. (1996), "Política urbana e competitividade", Sociedade e Território, 23, pp. 31-42.

DRAKAKIS-SMITH, D. (1989), "Urban social movements and the built environment: an analysis of housing provision in North Australia", Antipode, 21 (3), pp. 207-231.

ESTANQUE, E. (1999), “Acção colectiva, comunidade e movimentos sociais: para um estudo dos movimentos de protesto público”, Revista Crítica de Ciências Sociais, 55, pp. 85-111.

HACKWORTH, J. (2007), The Neoliberal City: Governance, Ideology and Development in American Urbanism, Nova Iorque, Cornell University Press.

HALL, T. (1998), Urban Geography, Londres, Routledge.

HALL, T. e P. HUBBARD (1996), “The entrepreneurial city: new urban politics, new urban geographies?", Progress in Human Geography, 20 (2), pp. 153-174.

HARVEY, D. (1989), The Condition of Postmodernity. An Enquiry into the Origins of Cultural Change, Oxford, Blackwell.

JESSOP, B. (2002), “Liberalism, neoliberalism and urban governance: a state-theoretical perspective"", in N. Brenner e N. Theodore (eds.), Spaces of Neoliberalism: Urban Restructuring in North America and Western Europe, Oxford, Blackwell, pp. 105-125. 
KÖHLER, B. e M. Wissen (2003), “Globalizing protest: urban conflicts and the global social movements", International Journal of Urban and Regional Research, 27 (4), pp. 942-951.

LEES, L.; T. Slater, T. e E. WYLY (2008), Gentrification, Londres, Routledge.

LEFEBVRE, H. (1974), La Production de l'Espace, Paris, Anthropos. (Edição inglesa: H. Lefebvre (2003), The Production of Space, Oxford, Blackwell).

LEFEBVRE, H. (1968), Le Droit à la Ville, Paris, Anthropos.

LEY, D. (1980), "Liberal ideology and the postindustrial city", Annals of the Association of American Geographers, 70 (2), pp. 238-258.

MATIAS FERREIRA, V. (1975), Movimentos Sociais Urbanos e Intervenção Política, Porto, Edições Afrontamento.

MAYER, M. (2007), “Contesting the neoliberalization of urban governance”, in H. Leitner et al. (eds.), Contesting Neoliberalism Urban Frontiers, Londres, Guilford Press, pp. 90-115.

MELA, A. (1999), A Sociologia das Cidades, Lisboa, Editorial Estampa.

MENDES, L. (2008), A Nobilitação Urbana no Bairro Alto: Análise de um Processo de Recomposição SócioEspacial, Lisboa, FLUL (policopiado).

MILLER, B. (2007), "Modes of governance, modes of resistance: contesting neoliberalism in Calgary”, em H. Leitner et al. (eds.), Contesting Neoliberalism Urban Frontiers, Londres, Guilford Press, pp. 223-249.

NICHOLLS, W. (2008), "The urban question revisited: the importance of cities for social movements", International Journal of Urban and Regional Research, 32 (4), pp. 841-859.

PECK, J. e A. TICKELL (2002), “Neoliberalizing space”, in N. Brenner e N. Theodore (eds.), Spaces of Neoliberalism: Urban Restructuring in North America and Western Europe, Oxford, Blackwell, pp. 33-57.

PICKVANCE, C. (2003), "From urban social movements to urban movements", International Journal of Urban and Regional Research, 27 (1), pp. 102-109.

PIMENTA DE FARIA, C. (2002), "Novos capítulos da crónica de uma morte sempre anunciada ou a crise do «welfare state" revisitada", Teoria \& Sociedade, 9, pp. 202-229.

PRUIJT, H. (2003), "Is the institutionalization of urban movements inevitable? A comparison of the opportunities for sustained squatting in New York City and Amsterdam", International Journal of Urban and Regional Research, 27 (1), pp. 133-158.

RODRIGUES, W. (2008), Cidade em Transição: Nobilitação Urbana, Estilos de Vida e Reurbanização em Lisboa, Lisboa, ISCTE (policopiado).

RODRIGUES, W. (1992), Retorno à Cidade e Emergência de Novos Estilos de Vida. O Fenómeno "Gentrification" como Exemplificação, Lisboa, ISCTE (policopiado).

SALGUEIRO, T. B. (1999), "Das mudanças territoriais às da gestão. Algumas notas”, Finisterra, 34 (67/68), pp. 153-160.

SAVAGE, M. e A. Warde (1993), Urban Sociology, Capitalism and Modernity, Londres, Macmillan. SCHECTER, S. (1978), The Politics of Urban Liberation, Montréal, Black Rose Books.

SMITH, N. (2005), "El redimensionamiento de las ciudades: la globalización y el urbanismo neoliberal”, em D. Harvey e N. Smith (eds.), Capital Financiero, Propiedad Inmobiliaria y Cultura, Barcelona, Universitat Autònoma de Barcelona, pp. 59-78. 
SMITH, N. (2002), "New globalism, new urbanism: gentrification as global urban strategy", Antipode, 34 (3), pp. 427-450.

SMITH, N. (2001), "Rescaling politics: geography, globalism, and the new urbanism", in C. Minca (ed.), Postmodern Geography. Theory and Praxis, Oxford, Blackwell, pp. 147-168.

SMITH, N. (1996), The New Urban Frontier. Gentrification and the Revanchist City, Londres, Routledge.

SMITH, N. (1987), "Gentrification and the rent gap", Annals of The Association of American Geographers, 77 (3), pp. 462-465.

SMITH, N. (1986), "Gentrification, the frontier, and the restructuring of urban space", in N. Smith e P. Williams (ed.), Gentrification of the City, Londres, Allen \& Unwin, pp. 15-34.

SMITH, N. (1979), "Toward a theory of gentrification: a back to the city movement by capital not people", Journal of the American Planning Association, 45, pp. 538-548.

SMITH, S. (1989), "Social geography: social policy and the restructuring of welfare", Progress in Human Geography, 13 (1), pp. 118-128.

STAHRE, U. (2004), "City in change: globalization, local politics and urban movements in contemporary Stockholm”, International Journal of Urban and Regional Research, 28 (1), pp. 68-85.

VIEIRA DE FARIA, c. (2009), As Cidades na Cidade. Movimentos Sociais Urbanos em Setúbal 1966-1995, Lisboa, Esfera do Caos.

WEXLER, M. (1999), “«Housing and social policy: an historical perspective on canadian-american differences - a reply”», Urban Studies, 36 (7), pp. 1177-1180.

WEXLER, M. (1996), “A comparison of canadian and american housing policies”, Urban Studies, 33 (10), pp. 1909-1921.

\section{NOTAS}

1. Não é preocupação central do presente texto problematizar a definição conceptual de gentrificação, pois existe uma abundante literatura científica que versa precisamente sobre esta questão, sendo o núcleo central das características do processo relativamente consensual entre a comunidade científica. Para aprofundar a discussão do conceito, remetemos para toda uma ampla bibliografia internacional discutida em português em Rodrigues (1992, 2008) e Mendes (2008).

\section{RESUMOS}

A propósito do desmantelamento das políticas de assistência pública de que o neoliberalismo dos governos urbanos se tem vindo a revestir; e de como a crise do welfare state está associada também à afirmação de intenções conservadoras, responsáveis pela produção de transformações no governo da cidade, discutiremos o conceito de cidade revanchista. Este denuncia como o discurso "regenerativo" da gentrificação funciona como mecanismo de legitimação do poder instituído e da mobilização de grande investimento público que, desviado do auxílio aos mais carenciados, funciona como subsídio aos mais ricos (Banca, instituições financeiras, grandes 
grupos económicos e de construção civil, etc.). O objectivo específico deste artigo é o de discutir o papel que cabe aos movimentos sociais urbanos na resistência aos novos produtos imobiliários fabricados pelas várias tendências de regeneração urbana na cidade contemporânea, especialmente na gentrificação da cidade centro.

The concept of the revanchist city will be discussed at the light of the dismantling of public assistance policies as a characteristic of neoliberal urban governments. The welfare state crisis, responsible for the production of urban governance transformation, will also contribute to the study of this concept. Besides, this concept shows how the regeneration discourse of gentrification functions as a mechanism of legitimising power and mobilising great public investment that is used to subsidise the richest ones, instead of benefiting those in need. Finance, great economical groups, civil construction groups, entrepreneurs, and governors, among others, contribute to this social polarisation. In this context, the objective of this paper is to discuss the role of urban social movements in the resistance to new housing products promoted by different urban regeneration trends in the contemporary city, especially in the gentrification of the city centre.

\section{ÍNDICE}

Keywords: gentrification, urban regeneration, urban social movements, revanchist city Palavras-chave: gentrificação, regeneração urbana, movimentos sociais urbanos, cidade revanchista

\section{AUTOR}

\section{LUÍS MENDES}

Instituto de Geografia e Ordenamento do Território da Universidade de Lisboa, Centro de Estudos Geográficos, Faculdade de Letras

luis.mendes@ceg.ul.pt 